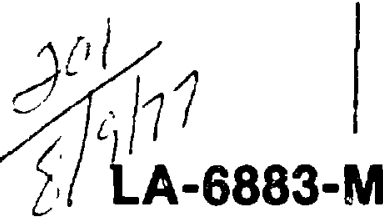

Manual

UC.32

Issued: July 1977

\title{
Coulometer Operator's Manual
}

\author{
A. L. Cristuolo
}

\section{O IA 95}

scientific laboratory

of the University of California

IOS ALAMOS. NEW MEXICO 87545

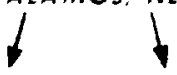

An Alfirmative Action / Equal Oppoitunily Employer 
Printed in the United States of Amcrica. Availabic from National Technical Information Service

U.S. Department of Commerce

5285 Port Royal Road Springficld, VA 22161

Price: Printed Copy \$3.50 Microfiche $\$ 3.00$

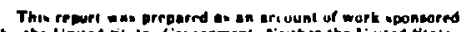

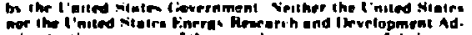
miaintrution. nar ens of ihrey emplareses nor ans of their con.

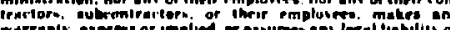

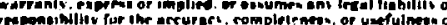

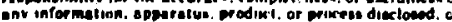

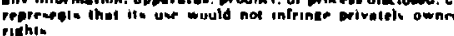


CONTENTS

1. INTRODUCTION ........................ 1

2. CONSTANT POTENTIAL OPERATION ............ 1

3. Maintenance ................ 6

APPENDIX A: DRAWING LIST . . . . . . . . . 14

APPENDIX B: SWITCH FUNCTION AND CONTROL SIGNAL

DESCRIPTION .......................

GLOSSARY

CCS - Coulometer control system

HP - Hewlett-Packard

MC - Microcontroller

PAR - Princeton Applied Research

TW - Thumbwhee]
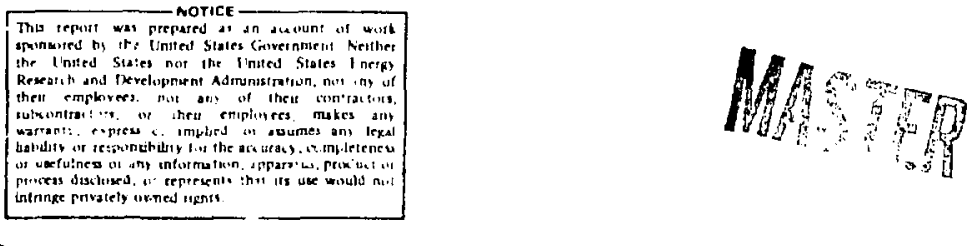
COULOMETER OPERATOR'S MANUAL

by

A. L. Criscuolo

ABSTRACT

The couloneter control system automates the cltration of urantum and plutonium as performed by the CMB-1 group. The system consists of a printer, microcontroller, and coulometer, all of which are controlled by an algorithm stored in the microcontrolier read-only memory. This manual describes the titration procedure using the coulometer control system, its theory and maintenance.

\section{INTRODUCTION}

This manual contains the information necessary to operate and maintain the coulometer control system (CCS). The procedure to conduct constant potential coulometrf.c measirements is first discussed. This is followed by a general discussion of the cuntrol algorithm accompanied by flow charts and a program list1ng. These should provile answers to nost of the detafled questions that may arise. Lastly, the information required to maintain the hardware is presented. This information includes wire 11st, schematics, and references to other manufacturers' documentation.

Figure 1 is a photograph of the CCS installed in its laboratory environment. The three subsysterns that comprise the CCS are the Hewlett-Packard (HP) printer, the E-5 8080 microcontroller (MC), and the Princeton Applied Research (PAR) coulometer.

The CCS should not be modified without first consulting with the E-5 MiniMirrocomputer Group, since most changes w111 have significant consequences.

\section{CONSTANT POTENTIAL OPERATION}

The constant potential coulometric measurement may be considered to consist of three major phases: 


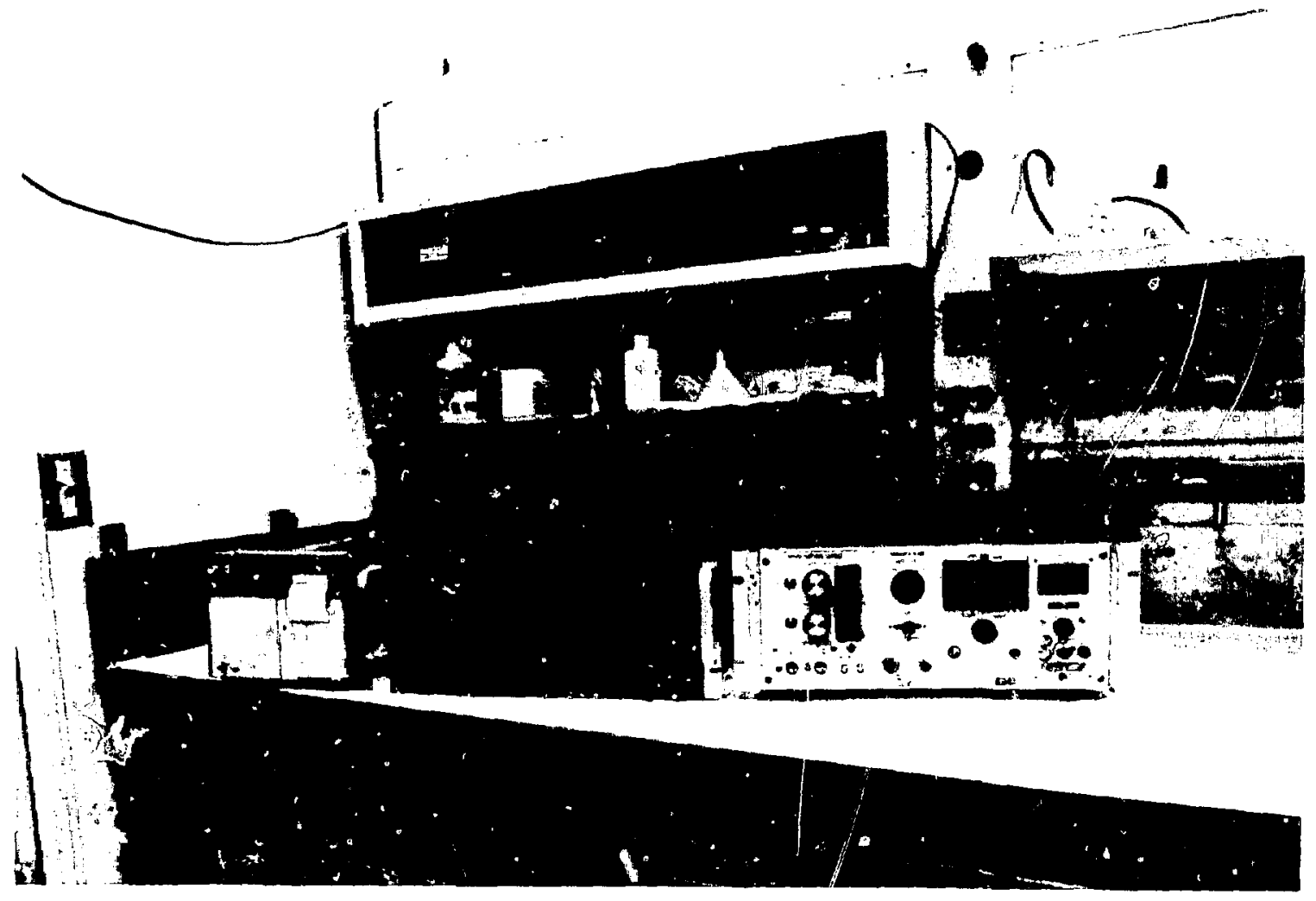

Fig. 1. Coulometer control system in a labor-cory environment.

\section{Ce11 preparation \\ 2. Instrumentation setup \\ 3. Automated titration and data printout}

The first phase is the same with the CCS and the manual system, so it will not be discussed here. The second phase consists of two procedures. One piocedure is for the initial setup of the inistrumentation and need only be checked during power turn-on. The second procedure needs to be conducted at the beginning of each measurement cycle; that is, each time a new cell is introduced to the coulometer. The automated titration phase is discussed below in general terms and in more detail in the maintenance section.

\subsection{Turn-on Procedure}

The turn-on procedure should be followed whenever the system has been left unat tended for more than a day. Befcre turning on the ac power, check the following: 
A. PAR Potentiostat Switch Setup

1. Ext. Trig. Switch - IN

2. Ext. Trig. Mode Switch - Track

3. Operating Mode Switch - Contr. E

4. Ext. Ce11/OFF/Dummy Ce11 Sw1tch - OFF

5. Local/Remote Switch - Remote

6. Voltage/Current Meter Sw1tch - Current

7. Reset Switch - Down

8. Current Range - $100 \mathrm{~mA}$

B. HP 5150A Printer

1. Print Command Switch (on rear) - LF

2. Rocker Switches $1,2,3,4,5$ - OFF

3. Rocker Switches 6,7 - ON

C. E-5 Microcontroller

1. Continuous/Step Switch - Continuous

2. Reset/Run - Run

D. Turn on the ac power to the PAR, HP, and E-5 respectively. If manual coulometric measurements are to be done only, it is not necessary to turn on the HP or E-5 electronics. For local measurements, the local/ remote switch on the PAR should be set to local.

E. Each time the ac power is removed from the E-5 electronicr, it is necessary to set the tide on the clock of the controller. Th1s is accomplished as follows:

1. Set the thumbwheel (TW) to read 003.

2. Push the start switch, then the load switch.

3. Set the TW to correspond with the month, then push the load switch.

4. Set the TW to correspond with the date of the month, push the load switch.

5. Set the TW to correspond with the hour. The hour Is based on a $24=$ hour military day not divided into a.m. and p.m. with zero hour at midnigit. Push the load switch.

6. Set the TW to correspond with the minute of the hour, then push :he load switch. 


\subsection{Setup for Each Cell}

Each time a new cell is introduced to the CCS, the parameters associated with that cell must be entered into the $\mathrm{E}-\mathrm{s}$ controller through the TW switches. The setting and display of these parameters is done as follows.

\subsubsection{Setting of Purameters.}

a. Set TW to read 002 .

b. Push start switch, then load switch.

c. Set TW to a 001 if cell contains plutonium, a 002 if cell contains uranium. Push the load switch.

d. The mass of the cell sample fia entered in chousands of micrograms. A four-digit number is entered, two digits at a time, starting with the most significant digits. For example, a sample welghing 2.1$\lrcorner 9 \mathrm{mg}$ would be entered as 21 (load switch), 39 (load switch).

e. Next, the number of the run must be entered. Thts is any twodigit number. Enter $\mathrm{OXX}$ on the TW and push the load switch.

2.2.2 Display of Parameters. To verify tihat the parameters of the cell were entered correctly, they may be displaycd on the printer by setting the TW to 000 , then pushing the start and load switches respectively.

2.2.3 Set Titration Potcnt1.2is. The values of potential A and potential $B$ must be set as weli as their respective polarity. Potential A switch must be depressed, as this potential is always run first by the controller.

\subsubsection{Initiating Coulometric Measurement Cycle. After performing the} necessary setup procedures the measurement is 1nltiated by entering a 004 on the TWs, then pushing the siart and load switches, respectively. The measurement cycle may end with any one of the following five messages. Messages are read from botrom to top.

a. Normal Message - The printer will display the following message. The $\mathrm{Xs}$ take on the appropriate values. The charge is displayed in coulombs. 


\section{CHARGE: $+X X X X . X X X X X X C L$ \\ ELAPSED TIME $X X: X X$ TITRATION STOPPED RUN: XX MASS : XXXXMICROGRAM \\ ELFMENT:U}

TIME $X X: X X: X X$ DATE $X X / X X$

TITRATION STARTED

b. Elapsed-T1me Error Message - If the mininum titration current 1s not attained within 25 minutes of the start of titration, the following message sccurs. The "POT" may be elther $A$ or $B$.

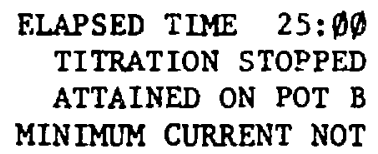

TIME XX:XX: XXX DATE $X X / X X$

TITRATION STARTED

c. Overcurrent Error Message: If a titration current in excess of five times the full-scale value occurs, the titration is stopped 1mmediately and the following error message is printed.

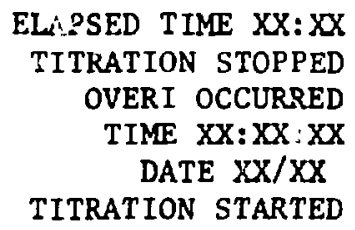

d. Overcharge Error Message: if a titration charge in excess of the coulometer range occurs, the titration is stopped immediately and the following message is printed. 


\section{ELAPSED TINE XX:XX \\ TITRATION STOFPED \\ OVER Q OCCURRED \\ TIME XX:XX:XX \\ DATE $X X / X X$ \\ TITRATION STARTED}

e. Overload-of-Current Ezror Message. If a current in excess of 1 A occurrs for more than $2 \mathrm{~s}$, the titration $1 \mathrm{~s}$ stopped 1mmed1ateiy and the following message is printed.

$$
\begin{array}{r}
\text { ELAPSED TIME } \mathrm{XN}: \mathrm{XX} \\
\text { TITRATION STOPPED } \\
\text { OVERLOAD OCCURRED } \\
\text { TIME XX: XX:XX } \\
\text { DATE XX/XX } \\
\text { TITRATION STARTED }
\end{array}
$$

2.2.5 Time Display. The time of day and date may be printed by entering a 001 on the TW, then pressing the start and load switches respectively.

2.2.6 Termination of Coulometric Meauuriment. Upon recelpt of one of the messages discussed in the previous paragraph, the operator ma. Initlate another measurement cycle after entering the cell parameters and setting the potential values.

2.2.7 Reset Function. The reset switch allows a command to be terminated before 1t reaches 1 ts conclusion. The reset switch may be used to correct data entry errors by terminating the command and then the operator may begin again. The controller w1ll not execute a second command unt1l the completion of 1 ts current comand. For examplia, a time-display command w1ll not be executed if a t1tration measurement is in progress.

If the operator notices a problem with the tidiration process, he may ierminate it by pressing the reset switch.

\section{MAINTENANCE}

Th1s section will discuss the design philosophy of the CCS for the purpose of providing background Information to the malntenance personnel s A system block dlagram is discussed to ald in 1dentifying system units, detalled interchassis wire lists are presented, schemat1cs of LASL-bullt devices are presented or referenced, and f?ow dlagrams of the software, as well as the program listing are discussed to a1d in 1dentifying which system unit is malfunctioning. 


\subsection{System Block Diagram}

The CCS cons1sts of three basic units, the PAR Model 179/173 potentlostat/ coulometer, the IP5150A thermal printer, and the E-5 MC. The units and their pertinent subunits are 1llustrated In F1g. 2.

The E-5 MC 1s the central control unit of the system. Comands are entered through the TW switch to direct the controller. Experiment parameters are also entered through the TWS. The MC controls the display messages on the HP priuter. When the "control coulometer" command is given, the MC takes control of the PAR coulometer unt1l completion of the titracion.

\subsection{Interchassis Wirlng}

The three systen units are interconnected through cables connected to the rear of the MC chassis. The detalled $p$ in/function assignment of these cables is given in Appendix A, Ref. D.I.

\subsection{Switch Function and Contiol S1gnal Description}

A description of each of the switches on the MC is provided in Append $\pm x B$. A description of the control signals from the MC, PAR, and HP are 1ncluded in Appendix $B$ also.

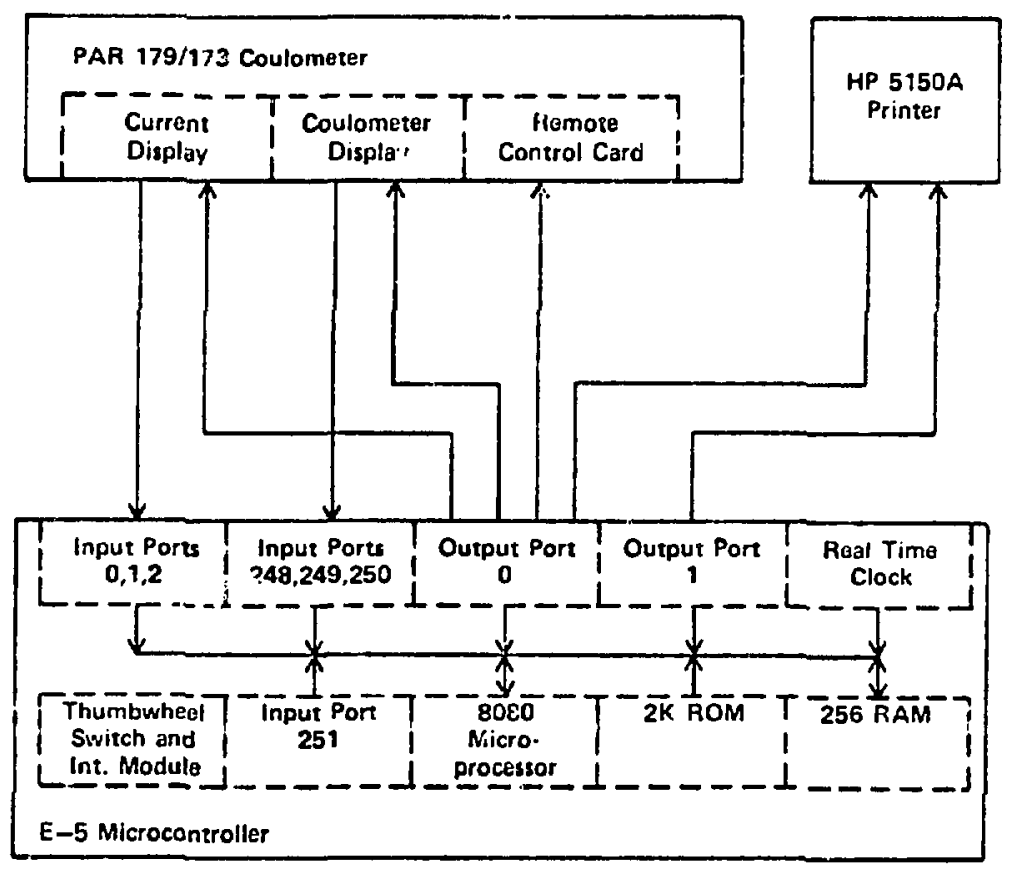

F1g. 2 .

System block diagram. 
$3.4 \quad$ Scinematics

The schematics, which describe the design of the MC mudules, are 1isted in Appendix A. These drawings may be obtalned from the $\overrightarrow{\mathrm{E}}-2$ Drafting section. 3.5 Flow Diagrams and Program Listing

The control algorithm is described in this section through the use of fluw diagrams and a program 11st1ng. The flow diagrame will act as a roed map of the program 11sting.

The flow diagrams are presented in a sequence of increasing deta11. The detalled flow diagrams are presented approximately in the order in whicis they occur in the program lising. The program listing is presented in Appendx A, Ref. $E$.

3.5.1 General Flow of Control. The supervisory program flow 1s 11lustrated in Fig. 3. The program is entered through a power-on or a reset. After Initlalizing the output ports and program parameters, the MC stays in an idle loop unt1l an interrupt occurs. The MC w111 service the interrupt and then return to the 1dle loop.

3.5.2 Thumbwheel Service Routine. The flow chart for the routine, which services the IW command switch, is 1llustrated In Fig. 4. When the start switch is depressed, an interrupt is generated that causes the MC to read the TW switch and execute the command that corresponds to the number set on the TW. Table I lists the commands and their TW setting.

The first reading from the TW after 1ts interzupt is interpreted as a command code. If subsequent readings are necessary, they are considered data for either the calendar clock or the cell parameters.

Because the routine disables the TW Interrupt, it will service only one command at a t1me. The command w11l be serviced to completton and then the MC w1ll accept a new conmand.

3.5.3 Command Routines. The routines, which execute the commands of Table I, are simllar in 1 เok. Consequently, only the last command w1ll be discussed. The general flow of the program is 1llustratad in Fig. 5. The detalled flow 1s shown in Fig. 6 .

3.5.3.1 General Flow. As can be seen in F1g. 5, the controller 1s pulled out of the wait loop by an interrupt frow the start switch. The MC takes the data in from the 'i'W switch, decodes the corresponding command, and executes the command. The command w111 be executed to completion before the MC wtil service another command from the TW. The calendar clock may interrupt the MC while 1t 


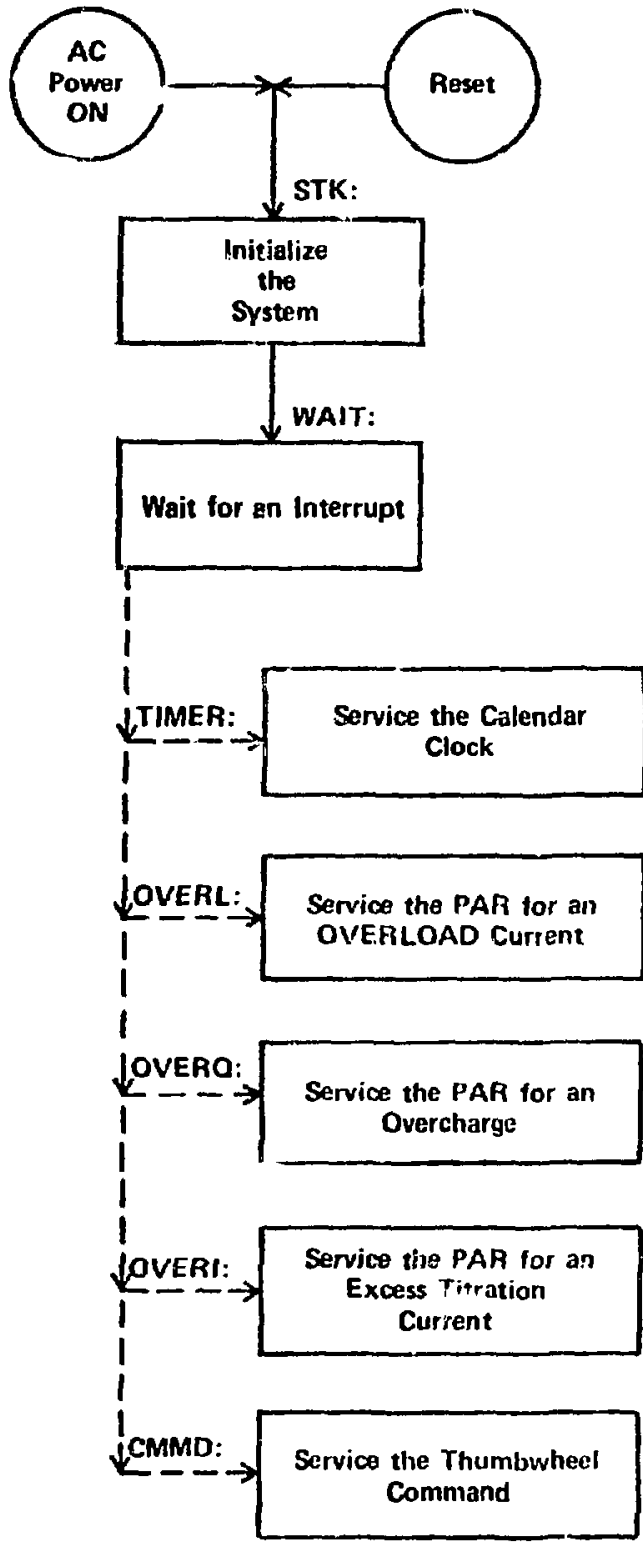

Fig. 3.

General flow of program. 


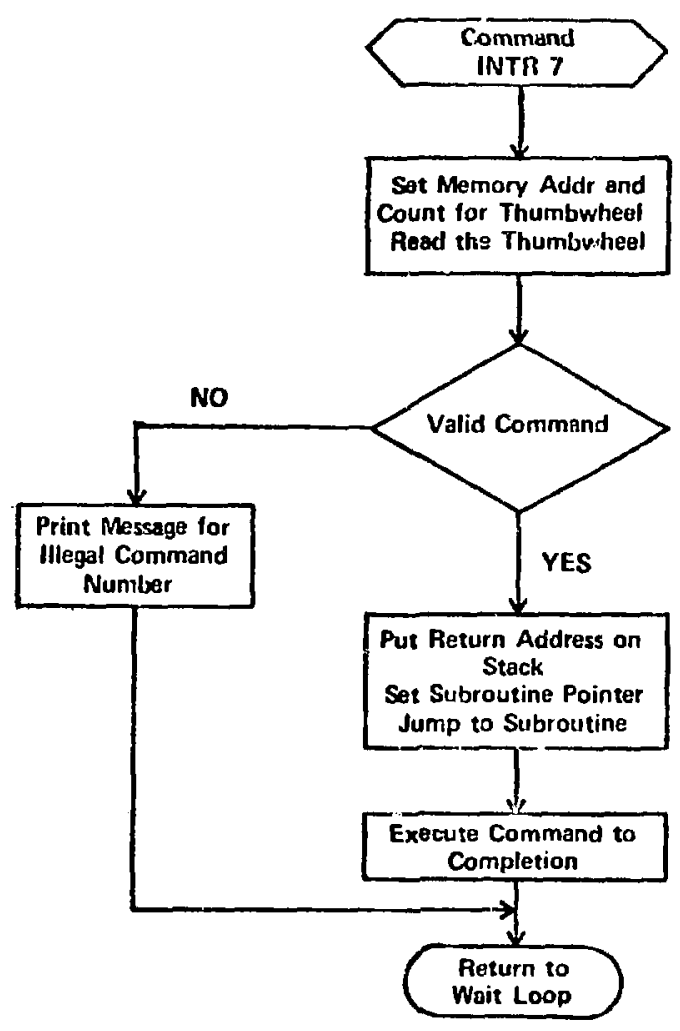

F1g. 4.

Thumbwheel service routine.

TABLE I

COMMAND/THUMBWHEEL SETTING

Thumbwheel

Setting

$000 \quad$ Print out the cell parameters.

001 Print out the date and time.

002 Input the cell parameters from the thumbwheel.

003 Input the date and time from the thumbwheel.

004 Perform a coulometric measisrement cycle. 
Is executing a command. However, the operation of the PAR is not affected by this. If one of the PAR "excess" conditions occurs, the appropriate message is printed and the $M C$ reinitializes the CCS.

3.5.3.2 Deta11 Flow. The detall flow of the MC coritrci, while executing a "control couloneter" command, is 1llustrated In Figs. 6 and 7. The MC conducts a titration at potential A until the minimum current is achieved, then 1 conducts the second titration at potential $B$ until the same minimum current is attaineu. When this current occurs the value of the total charge accumulated is displayed on the printer along with the other parameters assoclated with the measurement.

If the minimum current is not attained within 25 minutes of the start of titration, the process is halted and an error message is displayed. Also, if any of the "excess interrupta" occur (overload, overcharge, overcurrent), the titration will be stopped and the approprlate error message displayed. Some polnts are discussed below that may clarify certaln aspects of the control procedure.

a. The current meter on the PAR does not have the resolution required for the titration measurements, that is, less than $100 \mu \mathrm{A}$. Consequently, when the titration current becomes less than $200 \mu \mathrm{A}$, the $\mathrm{MC}$ no longer reads the current meter. Instead it reads the charge meter once per second, subtracts consecutive readings, and uses the result as the average current value for the $1-s$ incerval. In this manner, it is possible to resolve currents as low as $10 \mu \mathrm{A}$ when the titration current range switch is set for $100 \mathrm{~mA}$ full scale.

b. The actions taken in the flow dlagram boxes $D, E, F$, and $G$ are executed for potential $A$, but are not required. However, by including them, the procedure for $A$ and $B$ potentials becomes Identical, thus simplifying the software.

c. The charge meter display is 1imfted to four digits plus exponent, a1though the electronic counter driving the display has an 18-digit range. Therefore, to prevent the loss of any information, the charge meter is not reset irmediately after the citration current reaches 200 HA. Instead, the MC walts for the least significant digit of the charge meter to be updated before resetting the charge meter. This is fllustrated in boxes $D, E$, and $F$ of the flow diagram. 
3.5.4 Subroutine Flow D1agrams. The remainder of the flow diagrams are related to suwiuutines that art used by the supervisory routine, the TW routine, and/or the command routines. These flow dlagrams sre presented in Appendix A, Ref. E.1. It is belleved that the commented listing and the flow dlagrams are adequate to convey an understanding of the contro: sequence.

CONTROL COULOMETER COMMAND

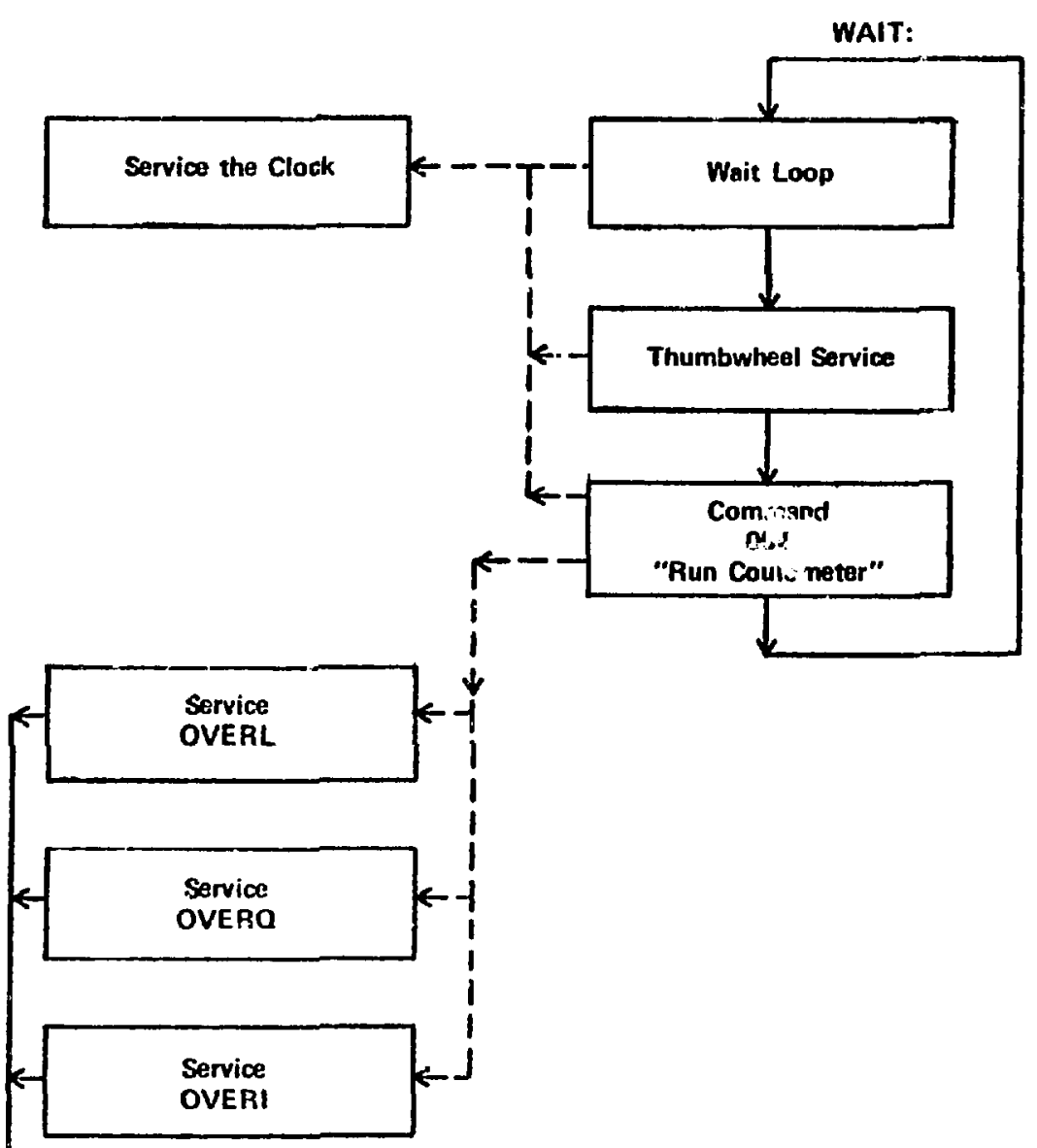

$\rightarrow$ Return to STK: to initialize system

F18. 5.

General flow for commend to control coulometer. 

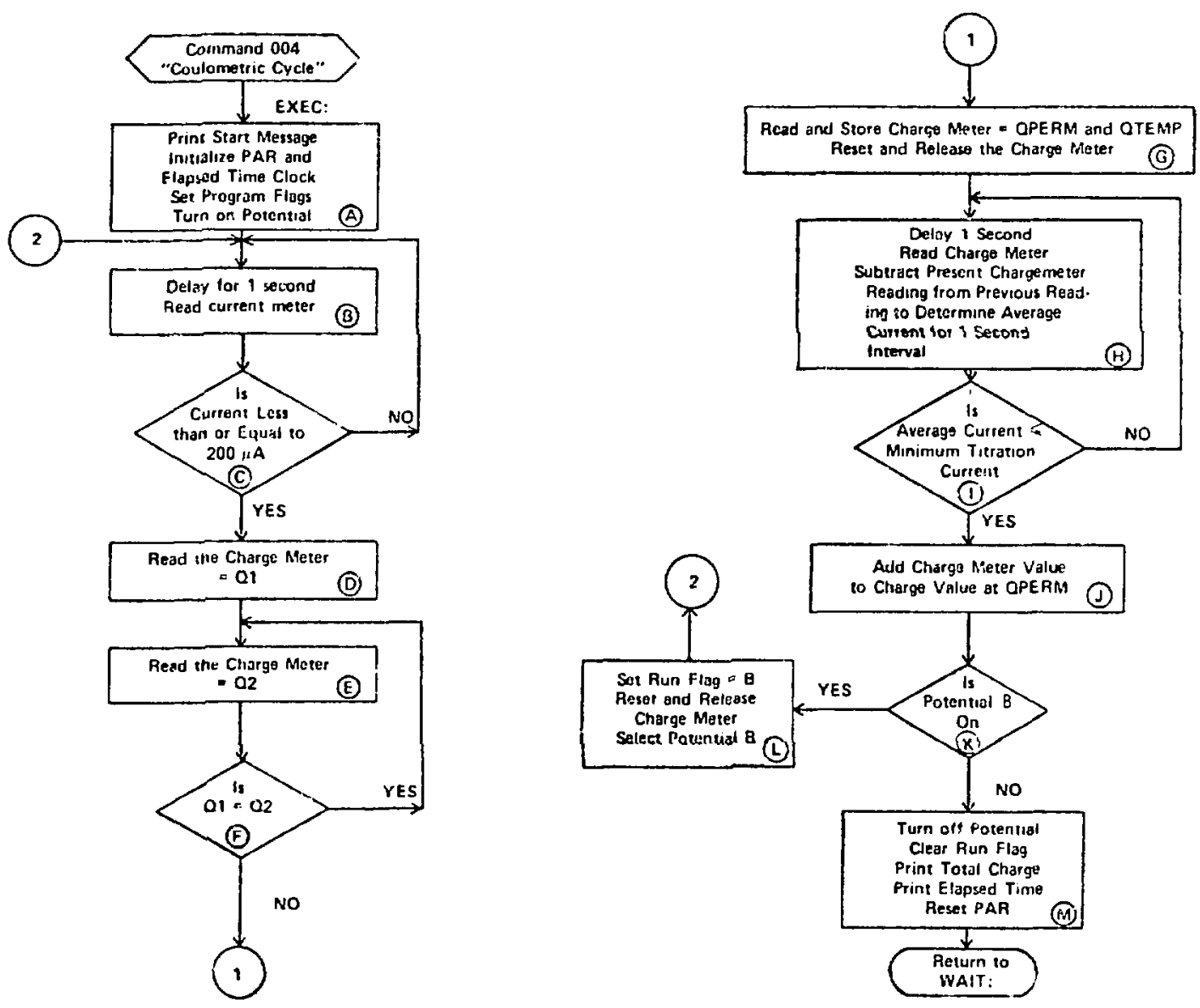

Fig. 6.

Detalled flow of control coulometer command. 


\section{APPENDIX $A$}

\section{DRAWIMG LIST}

A. Princeton Applied Research Corp. Model 179/173 C

1. Model 173 - Manual M186B, January 1974.

2. Model 179 - Mlanual M198, August 1973.

3. "Modification of PAR Coulometer," Group E-5 memo dated Jaauary 14, 1977, from A. Criscuolo to D. Jackson; "Modification to PAR for Remote Contro1," Group E-5 memo dated Apr11 13, 1977 from A. Criscuolo to D. Temer.

B. HP Printer Model 5150A

1. Manual Number 0515C-90002, September 1974.

C. E-5 Microcontroller

1. Microcontroller CPU, LASL 4Y-168169.

2. 4K PROM, LASL 4Y-168399.

3. PAR Interface Module, LASL 4Y-168179.

4. Microcontroller Bin, LASL 4Y-168185.

5. E-5 Microcontroller User's Manual, Los Alamos Srlentific Laboratory informal report, LA-6826-M.

D. System Wiring

1. "Interchassis Wire List," Group E-5 memo dated Apr11 21, 1977, from A. Criscuolo to D. Temer.

E. "Progran Listing and Flow Charts," Group E-5 memo dated April 21, 1977, from A. Criscuolo to D: Temer. 


\section{A.PENDIX B}

SWITCH FUNCTION AND CONTROI SIGNAL DESCRIPTION

\section{Signal Descziption for Coulometer Control}

\section{Potentiostat Signals}

1. The potentiostat current display Is contalned at Inport 0 and Inport 1.

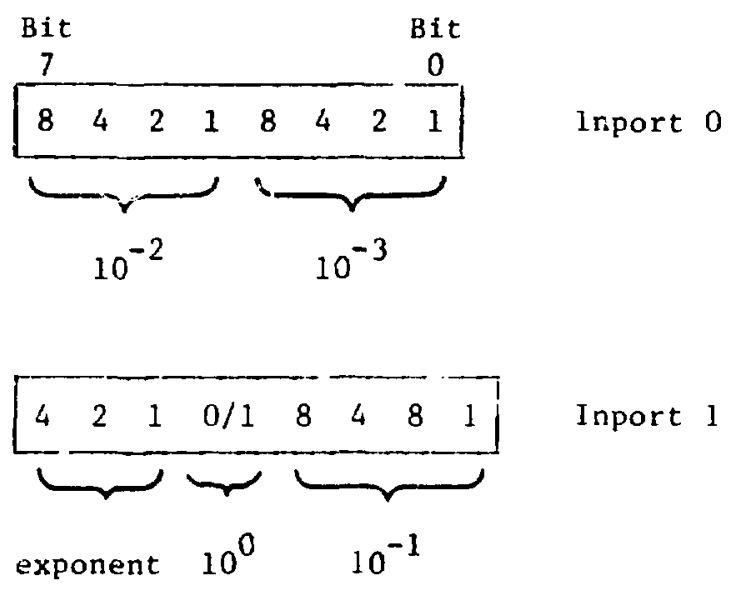

2. Inhiblt Trigger: This control line allows the micro to control the current display. When this line is HI the display will free run as normal. When this line 1s LO, the display will be updated only on command from the micro. This allows the micro to take stable data from the potentiostat. This line 1s asgigned to Outport 0, Bit 3.

3. External Trigger: When Inh1b1t Tr1gger 1s 20 , the transition of External Trigger from a LO to HI will cause the current display to update. This I1ne Is assigned to Outport 0, Bit 2 .

4. Update Complete: This line indicates to the micro that the display has completed 1 ts update and valid data are present at Inports 0,1 . Th1s signal is assigned to Inport 3, B1t 0 . A LO indicates valid data.

5. Polarity: This line indicates the sign of the current display. Assigned to Inport 2, Bit 0 . A HI is plus.

6. Overrange: A HI 1ndicates the current has exceeded the range setting. Assigned to Inport 2, B1t 1 . 
7. Potential Trigger: A transition from a HI to a LO selects potential A. A transition frame Lo to a HI selects potential B. Assigned to Outport 0 , B1t 1.

8. Potential OFF: A Lo removes the potential from the electrodes. This is equivalent to the of position on the dummy/cell silde switch. This line 10 assigned to Outport 0, Bit 0 .

9. Overload: When thls signal is asserted, the potentlostat is being overloaded. This line is assigned to Interrupt 1, the second highest priority interrupt. This allows 1mmediate entry into a program that will turn off the potentlostat by asserting the Zero E signal.

10. External Ce11: A to applies the selected potential (A or B) to the cell being analyzed. This line is assigned to outport 0 , Bit 6.

\section{Coulometer Signals}

1. The coulometer display is contained at Inports $248,249,250$ decimal.

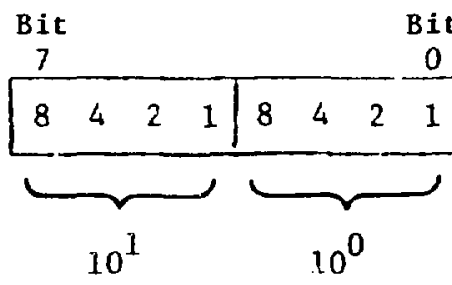

Inport $248_{10}(\mathrm{FBH})$

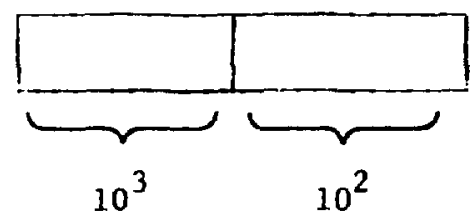

Inport 249

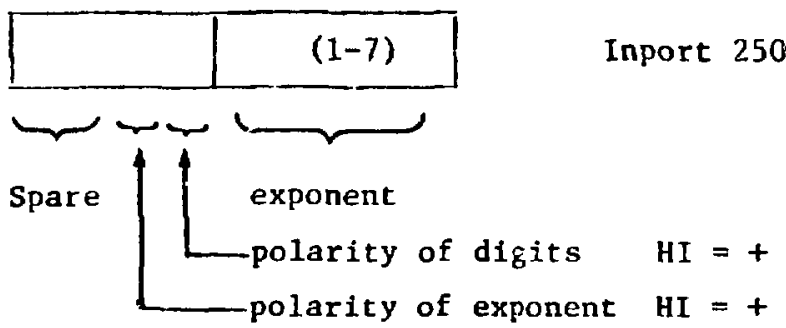


2. Reset: A Lo signal from the micro will reset the display. Assigned to Outport 0 , Bit $\{$.

3. Print Cnd: A LO signal from the micro will freeze the digital output of the coulometer so that the micro will read stable data. Assigned to Outport 0 , Bit 5.

4. V-F/Inhibit: A Lo sigaal from the micro will freeze the coulometer display. This signal can be used to control the start of the coulomb count. This signal is not used.

5. Over I: A LO signal frcm the co'llometer indicates that the current range has been cxceeded. Assigned to Inport 2, Bit 2 and $\overline{\operatorname{Intr} 6 .}$

6. Over Q: A Lo signal from the coulometer Indizates that the charge range has been exceeded. Assigned to Irport 2, B1t 3 and $\overline{\text { Intr } 5 .}$

\section{HP Printer Signals}

1. The ASCII rharacter code is output from the micro to the printer on Outport 1. The code is defined on PP. 2-17 of the HP-5150A printer manual. The port bit assignments are as follows.

\begin{tabular}{|c|c|c|c|c|c|c|c|}
\hline $\begin{array}{c}\text { Bit } \\
7 \\
\end{array}$ & & & & & & $\begin{array}{r}3 \\
0 \\
\end{array}$ & \\
\hline b7 & b6 & b5 & b4 & b3 & $\mathrm{b} 2$ & b & Outport 1 \\
\hline
\end{tabular}

The " $b$ " refers to the ASCII chart and are Lo true; that 1 , a 1 on the ASCII chart is a 0 th the output port.

2. DAV: A HI indicates to the printer that data are waiting to be sent. A LO indicates valid data are being sent. Assigned to Out port 0 , Bit 7 .

3. NRFD: A LO Indicates that the printer is not ready to take new data. Assigned to Inport 2 , Bit 7 .

4. NDAC: A HI indicates that the printer has accepted the new data. Assigned to Inport 2, Bit 6 .

\section{Micro Signals}

1. Reset: Momentary switch that causes the micro to return to the first ReadOnly Memory Address. Also clears all ports and the HP printer.

2. Start: Momentary switch that asserts an interrupt on priority level 7 (lowest leve1). 
3. Continuous: Alternate switch that allows the micro to run continuously when in the down position and halts the micro when in the up position.

4. Advance: Momentary switch that 1s active when the Continuous switch is up. When the Advance swttch is pushed, the micro will execute one machine cycle. This may be one-third of an instruction or one complete in.3iruction.

5. Sync: This LED lights when the micro 1s running.

6. Load: This momentary switch loads the contents of the TW switches into Inport 251.

7. Valid Data: Th1s signal indicates to the micro that new data have been loaded from the TWs. A LO on Inport 2, B1t 4 indicates new data.

8. Command Switch: These three TW switches provide binary data, in BCD code, to the micro through Inport 25.1 .

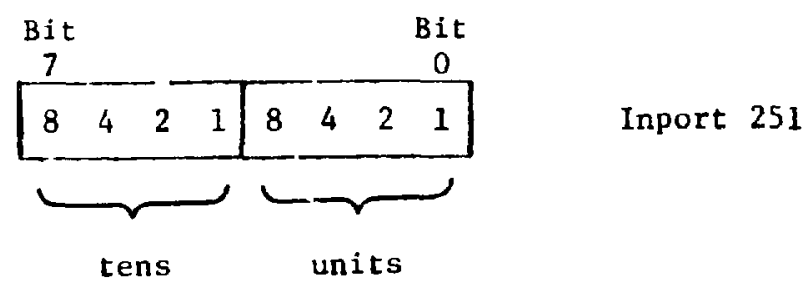

9. Real Time Clock Interval: A real time clock is assigned to Interrupt 6 to provide accurate measure of time intervals. The interrupt is automatically reset when the micro accepts $1 t$. The frequency of the interrupt is selectable by decode from 1 per $10 \mu \mathrm{s}$ to 1 per $\mathrm{s}$. The frequency $1 \mathrm{~s}$ selected by a set of switches on the printed circult board. Only one switch may be on at any time.

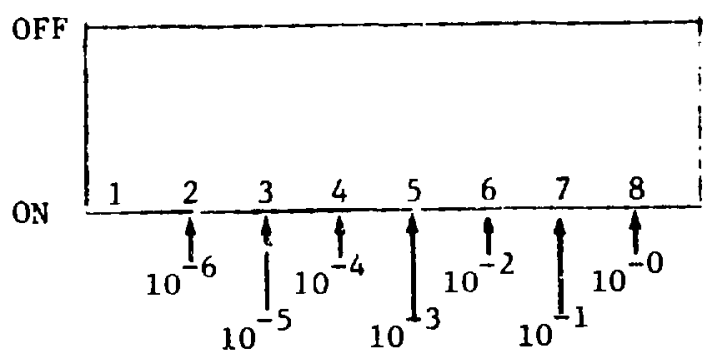

Switch located

on socket 204 